\title{
Alkalistable endo- $\beta$-1,4-xylanase production from a newly isolated alkalitolerant Penicillium sp. SS1 using agro-residues
}

\author{
Bijender Kumar Bajaj • Mukul Sharma • \\ Sunny Sharma
}

Received: 27 January 2011/ Accepted: 10 May 2011/Published online: 7 June 2011

(C) The Author(s) 2011. This article is published with open access at Springerlink.com

\begin{abstract}
Thermostable and alkalitolerant xylanases have got intense research focus due to their vast applications in various industries including pulp and paper, food, feed, textile, biofuel, etc. In the present investigation, a Penicillum sp. SS1 isolated from degrading woody material was found to produce moderately thermoactive and alkalistable endo- $\beta$-1,4-xylanase (xylanase). Maximum xylanase production was observed after fourth day of fermentation (43.84 IU/ml). The organism produced substantial quantities of xylanase using agricultural residues like wheat bran $(20.6 \mathrm{IU} / \mathrm{ml})$, rice bran $(21.8 \mathrm{IU} / \mathrm{ml})$ and sawdust $(10.7 \mathrm{IU} / \mathrm{ml})$ as carbon sources. The enzyme preparation was totally free of filter paper activity (FPase) and possessed negligible carboxymethyl cellulase (CMCase) activity; this could be an important feature of enzyme if the intended application of enzyme is in pulp and paper industries. Among nitrogen sources examined, yeast extract supported maximum xylanase production $(45.74 \mathrm{IU} / \mathrm{ml})$, and was followed by soybean meal $(22.2 \mathrm{IU} / \mathrm{ml})$ and ammonium sulphate $(20 \mathrm{IU} / \mathrm{ml})$. Maximum xylanase production was observed at initial medium $\mathrm{pH} 9(25.6 \mathrm{IU} / \mathrm{ml})$; however, at pH 8 and 10 also significantly high enzyme titre was observed (24 and $21.2 \mathrm{IU} / \mathrm{ml}$, respectively). Thus, Penicillium sp. SS1 displayed capability of growing and
\end{abstract}

Bijender Kumar Bajaj · M. Sharma · S. Sharma School of Biotechnology, University of Jammu, Jammu 180 006, India

Present Address:

Bijender Kumar Bajaj ( $\square)$

Biotechnology and Fermentation Group, Department of Animal

Sciences, Gerlaugh Hall, Ohio Agricultural Research and

Development Centre (OARDC), The Ohio State University,

1680 Madison Avenue, Wooster, OH 44691, USA

e-mail: bkbajaj1@ rediffmail.com producing xylanase at high alkaline $\mathrm{pH}(8-10)$. Maximum xylanase activity was reported at $50{ }^{\circ} \mathrm{C}$, however, significantly high activity was observed at $60{ }^{\circ} \mathrm{C}(65.4 \%)$, however, at $70-80{ }^{\circ} \mathrm{C}$ activity was lost considerably. At $50-60{ }^{\circ} \mathrm{C}$ the enzyme retained very high activity up to 30-60 min (91-100\%), however, prolonged incubation (90 min) caused considerable activity reduction (residual activity $63-68 \%$ ).

Keywords Xylanase - Penicillium sp. A Alkalistable · Thermoactive - Wheat bran · Rice bran

\section{Introduction}

In recent years, increasing concern over preserving natural resources and the environment has initiated a growing interest in application of microbially produced enzymes in industrial processes. Xylan degrading enzymes have attracted much attention because of their applications in industrial processes such as the modification of cerealbased food stuffs, improving the digestibility of animal feed stocks, bioconversion of lignocellulosic materials and agro-wastes to fermentable products, and pre-bleaching of paper pulps (Kuhad and Singh 1993; Beg et al. 2001). Xylanases are glycosidases $(O$-glycoside hydrolases, EC 3.2.1.X) which catalyze the endohydrolysis of $1,4-\beta-\mathrm{D}$ xylosidic linkages in xylan. The complete hydrolysis of xylan involves the synergistic action of an array of main and side-chain-cleaving enzymes including endo- $\beta-1,4-$ xylanase, $\beta$-D-xylosidase, $\alpha$-1-arabinofuranosidase, $\alpha$-glucuronidase and acetyl xylan esterase, but hydrolysis by endo- $\beta$-1,4-xylanase (or simply xylanase) is considered as one of the key reactions in the process (Kuhad and Singh 1993; Beg et al. 2001). As hemicelluloses are the second 
most abundant renewable resource, and xylan constitutes the major component of hemicelluloses, therefore, xylanolytic enzymes derived from microbial sources could be of great industrial, environmental and strategic significance (Sharma and Bajaj 2005; Sudan and Bajaj 2007; Liu et al. 2008; Bajaj and Singh 2010; Nagar et al. 2011). The increasing interest in xylanases in recent years has mainly been due to their potential applications in the pulp and fiber processing industries. Xylanases promote bleaching through the hydrolysis of relocated and re-precipitated xylan on the surface of the pulp fibre, this results in better chemical penetration and consequently improved lignin extractability. The application of xylanases in pulp and paper reduces the need for toxic chemicals such as chlorine and chlorine dioxide, during the bleaching process of pulps and, thus, promote the development of environmentfriendly industrial process (Singh et al. 2011). Prebleaching of the paper pulp requires the use of cellulase-free xylanases, since cellulases may adversely affect the quality of the paper pulp by destroying the structure of cellulose and, thus, diminish the quality of pulp (Kuhad and Singh 1993; Beg et al. 2001).

For successful industrial applications, xylanases must be thermostable, alkalistable and robust so that they can withstand the harsh industrial process conditions. Most of the xylanases characterized so for show optimal activity at acidic, neutral or slightly alkaline $\mathrm{pH}(7-8)$ and at temperature between 40 and $60{ }^{\circ} \mathrm{C}$. In the search for thermostable and alkalistable xylanases, microbial diversity has been extensively exploited (Bajaj and Singh 2010; Singh et al. 2011; Nagar et al. 2011). Furthermore, utilization of low-cost agriculture-based crude substrates can play a crucial role in overall cost-reduction for bulk production of xylanases for industrial applications.

Keeping in view the importance of thermostable and alkalistable xylanases in various industrial sectors, the present investigation was aimed at production and characterization of thermoactive and alkalistable xylanase from a newly isolated alkalitolerant Penicillium sp. SS1.

\section{Materials and methods}

\section{Isolation of xylanolytic fungi}

For isolation of fungi, samples (alkaline soil, cow-dung manure, degrading sawdust, bagasse, poultry waste etc.) were suspended $(5 \%, \mathrm{w} / \mathrm{v})$ in normal saline, and suspension was appropriately diluted and spread plated $(100 \mu \mathrm{l})$ on PDA (potato-dextrose-agar) and plates were incubated at $30{ }^{\circ} \mathrm{C}$ for 4 days. The fungal colonies appeared were examined microscopically and purified by re-streaking on PDA. All the fungal isolates were maintained on PDA slants at $4{ }^{\circ} \mathrm{C}$.
For analyzing xylanolytic activity of the isolated fungi, all the isolates were spotted $(2-3 \mathrm{~mm})$ on the xylan agar (each, \%, w/v, ammonium sulphate 0.3 , potassium dihydrogen phosphate 0.3 , ammonium acetate 0.6 , oat spelt xylan 0.5 , agar $2 ; \mathrm{pH} 8-10$ ). The plates were incubated at $30{ }^{\circ} \mathrm{C}$ for 4 days. Colonies developed were assayed for xylanase producing ability by Congo red staining (Sudan and Bajaj 2007). The colonies were flooded with $0.1 \%$ (w/v) Congo red for $15 \mathrm{~min}$ and then washed three times with $1 \mathrm{M} \mathrm{NaCl}$ for $15 \mathrm{~min}$ each. Fungal colonies showing clear zones around them were considered positive for xylanase production, and the one (isolate SS1, identified as Penicillium sp. and designated as Penicillium sp. SS1) which showed the biggest halo was selected and further subjected to submerged fermentation for xylanase production.

Fermentation for analyzing growth and enzyme production

The selected organism Penicillium sp. SS1 was grown on PDA plates for 4 days and three discs $(2 \mathrm{~mm}$, each) of fungal biomass were cut and inoculated into $100 \mathrm{ml}$ of xylanase production medium (same composition as of above mentioned xylan agar but minus agar, and $\mathrm{pH} 7-10$ ) contained in Erlenmeyer flasks of $250 \mathrm{ml}$ capacity. Flasks were incubated on a shaker-cum incubator (Innova, New Brunswick, USA) at $30^{\circ} \mathrm{C}(180 \mathrm{rpm})$. After suitable intervals of time, samples were withdrawn, centrifuged at $10,000 \times g$ for $5 \mathrm{~min}$ (Sigma $3 \mathrm{~K} 30, \mathrm{UK}$ ) and supernatant was considered to be equivalent to crude enzyme and was used for assaying xylanase activity. For determining the growth of the organism, the mycelial mass was filtered through Whatman no. 1 filter paper, and the biomass obtained was weighed after appropriately drying it.

Determination of inducible/constitutive nature of xylanase, and exo/endoxylanolytic activity

Fermentation was conducted in xylanase production medium, and in the medium in which xylan of the production medium was replaced with glucose $(0.5 \%, \mathrm{w} / \mathrm{v})$, at $30^{\circ} \mathrm{C}$ under shaking $(180 \mathrm{rpm})$ for $96 \mathrm{~h}$. The fermentation broth was centrifuged and the supernatant from both the media was used for assaying the xylanase activity. The supernatant was loaded at the rate of $50 \mu \mathrm{l}$ in the wells (diameter, $7 \mathrm{~mm}$ ) cut in the xylan agar plates. The plates were incubated for $2-4 \mathrm{~h}$, and then subjected to Congo red staining.

The exo/endoxylanolytic activity of the Penicillium sp. SS1 xylanase was examined by carrying out thin layer chromatography (TLC) on silica gel plates (Kosugi et al. 2001). The spots of standard xylose, standard xylan, and xylanase-treated xylan ( $1 \mathrm{ml}$ of $0.5 \%$ xylan was incubated with $200 \mu \mathrm{l}$ of xylanase for $24 \mathrm{~h}$ at $37^{\circ} \mathrm{C}$ ) were applied, 
and TLC was run using acetone-ethyl acetate-acetic acid $(2: 1: 1, v / v / v)$ as solvent system. The plates were visualized by spraying with $1: 1(\mathrm{v} / \mathrm{v})$ mixture of $0.2 \%$ methanolic orcinol and $20 \%$ sulphuric acid.

Xylanase, carboxymethyl cellulase (CMCase) and FPase assay

Xylanase activity was assayed using $0.5 \%$ xylan in suitable buffer (Tris buffer, $50 \mathrm{mM}, \mathrm{pH} 8$ ) as the substrate at $45^{\circ} \mathrm{C}$. The reducing sugars released were assayed by dinitrosalicylic acid (DNSA) method using xylose as standard (Miller 1959). One unit of enzyme activity (International Unit, IU) is defined as the enzyme necessary to release $1 \mu \mathrm{mol}$ of reducing sugar or xylose equivalent per min under assay conditions.

In the same enzyme preparation CMCase and FPase were also assayed by employing DNSA method using carboxymethyl cellulose and filter paper as substrates, respectively (Sharma and Bajaj 2005; Sudan and Bajaj 2007). One unit (IU) of CMCase or FPase was defined as the amount of enzyme required to release $1 \mu \mathrm{mol}$ of reducing sugar equivalent per min under the assay conditions.

Xylanase production using alternate carbon and nitrogen sources

To study the effect of agriculture-based crude carbon sources on xylanase production the xylan of the xylanase production medium was replaced with alternatives like wheat bran, rice bran or sawdust $(1 \%, \mathrm{w} / \mathrm{v})$, as sole carbon source in the medium. Crude substrates were first crushed and then steam hydrolyzed by autoclaving (15 psi for $15 \mathrm{~min})$ and then used in the medium (1\%, w/v). Similarly, to analyze the effect of alternative nitrogen sources on xylanase production, the normal nitrogen source of the production medium was replaced with alternative nitrogen sources viz. yeast extract, urea, soybean meal or peptone $(0.5 \% \mathrm{w} / \mathrm{v})$, and fermentation was conducted as usual.

Effect of initial medium $\mathrm{pH}$ on xylanase production

The initial $\mathrm{pH}$ of xylanase production medium containing xylan $(1 \%, \mathrm{w} / \mathrm{v})$ as carbon source and yeast extract $(0.5 \%$, $\mathrm{w} / \mathrm{v}$ ) as nitrogen source, was adjusted to 8,9 or 10 using $\mathrm{Na}_{2} \mathrm{CO}_{3}(2 \%, \mathrm{w} / \mathrm{v})$ and fermentation was conducted.

Effect of temperature and $\mathrm{pH}$ on xylanase activity, and thermostability of xylanase

For studying the effect of temperature on enzyme activity, the enzyme assay mixture was incubated at different temperatures $\left(30-90{ }^{\circ} \mathrm{C}\right)$ and enzyme activity was determined. For determining effect of $\mathrm{pH}$ on enzyme activity, different buffers $(50 \mathrm{mM})$ were used in the assay mixture (citrate buffer for $\mathrm{pH} \mathrm{3,4,5}$ and 6; tris buffer for $\mathrm{pH} \mathrm{7,8}$ and 9; glycine- $\mathrm{NaOH}$ buffer for $\mathrm{pH} 10$ ) and activity was assayed. The thermostability of the enzyme was tested by pre-incubating the enzyme preparation at various temperatures $\left(50-90{ }^{\circ} \mathrm{C}\right)$ for different intervals of time (30-90 $\mathrm{min}$ ) and then assaying the residual activity.

All the analytical experiments were set in triplicates and the results represent the mean of three different experiments, standard deviation was determined and coefficient of variation was within $10 \%$.

\section{Results and discussion}

\section{Xylanolytic organism}

Of the 23 fungal isolates examined, the isolate SS1 produced the largest halo on xylan agar plates upon Congo red staining. Therefore, this isolate was selected for further studies. The isolate SS1 formed powdery colonies on xylan agar plate. Colonies were yellow coloured after 4 days of incubation and reverse was dark yellow. Microscopic examination of the morphology of the organism revealed that it was Penicillium sp., and the organism was designated as Penicillium sp. SS1.

Time course of growth and xylanase production

Xylanase production and growth were studied at $30{ }^{\circ} \mathrm{C}$ for 6 days in production medium $(\mathrm{pH} 8)$ containing $1 \%$ xylan as carbon source. It was found that xylanase production started from second day and reached a maximum on the fourth day $(43.84 \mathrm{IU} / \mathrm{ml})$, and then remained almost constant (Fig. 1). The growth and xylanase production went parallel up to fourth day but after that no further increase in enzyme production was observed, however, growth kept on increasing till sixth day. Similar trend was observed when growth and xylanase production were examined at $\mathrm{pH} 7.0$, i.e. maximum enzyme production occurred at fourth day of fermentation $(43.81 \mathrm{IU} / \mathrm{ml})$ while increase in growth continued up to sixth day (data not shown). Most of the earlier reports indicate that maximum xylanase production by fungi occur after 4-5 days of fermentation (Carmona et al. 1998; Ruckmanl and Rajendran 2001; Shah and Madamwar 2005; Sudan and Bajaj 2007; Murthy and Naidu 2010). However, Penicillium sp. ZH-30 produced maximum xylanase after 3 days of fermentation ( $\mathrm{Li}$ et al. 2007). It would appear that the maximum enzyme production stage of any organism is largely dependent upon the type of microbial strain and its genetic make-up as well as on 


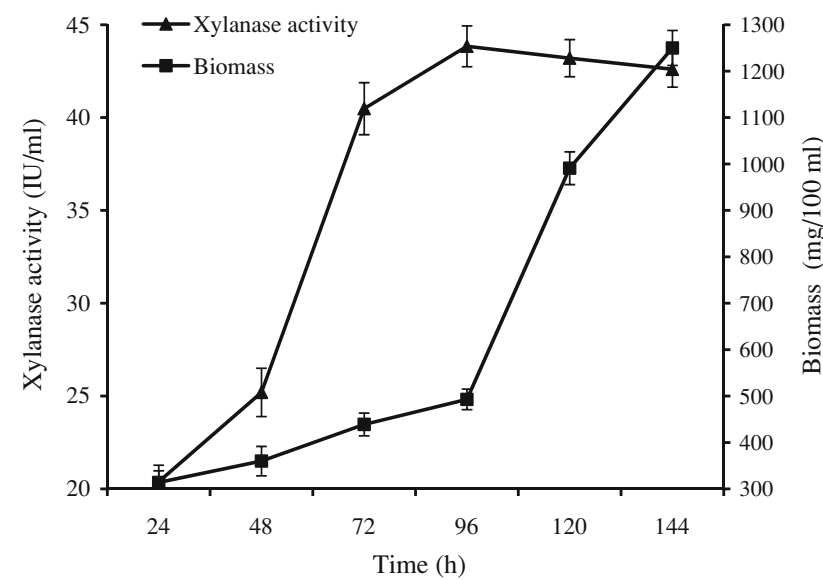

Fig. 1 Growth and time-course of xylanase production by Penicillium sp. SS1. Fermentation was conducted in production medium under shaking $(180 \mathrm{rpm})$ at $30^{\circ} \mathrm{C}$, and biomass and xylanase produced were assayed. Error bars show standard deviations

cultural and environmental conditions during the growth of the organism.

Inducible and endoxylanolytic nature of xylanase

When the xylan of the production medium was replaced with glucose, no xylanase production was observed as indicated by the absence of clear zone upon Congo red staining on xylan agar, however, as expected enzyme was

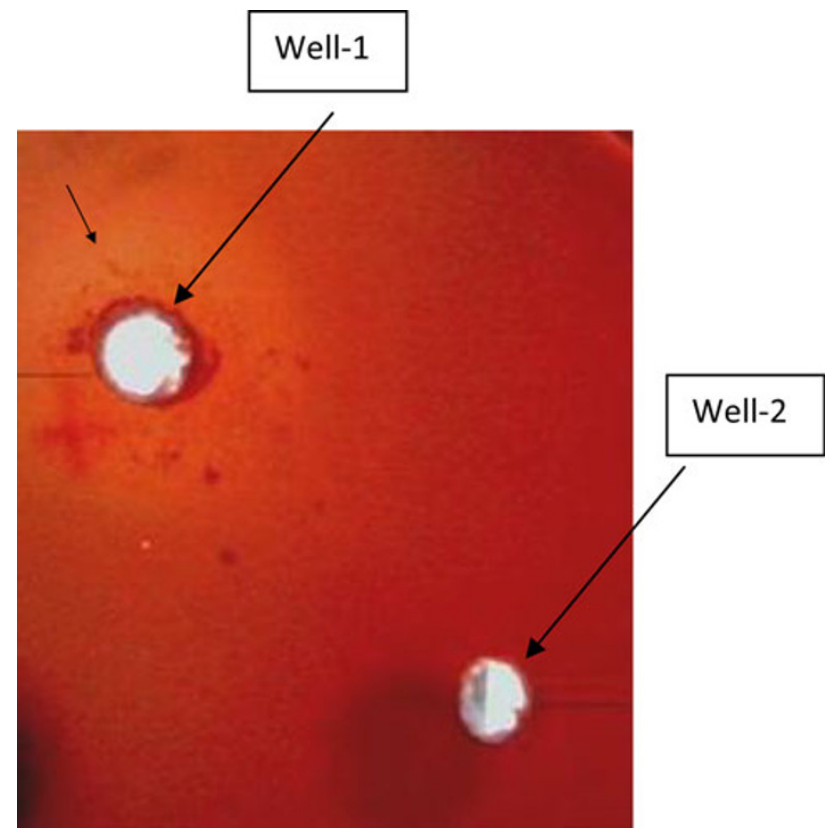

Fig. 2 Demonstration of inducible nature of Penicillum sp. SS1 xylanase on xylan agar plate by Congo red staining. Well-1 was loaded with cultural supernatant from medium with xylan as carbon source, well-2 was loaded with cultural supernatant from medium with glucose as carbon source. Arrow indicates zone of clearance produced when organism was cultivated in medium with xylan as carbon source (Fig. 2). Thus, the Penicillium sp. SS1 xylanase is inducible in nature and not of constitutive nature. Most of the microbial xylanases reported are of inducible in nature (Shah and Madamwar 2005; Sudan and Bajaj 2007; Singh et al. 2011), however, constitutive xylanases are also known (Bocchini et al. 2008). Furthermore, the Penicillium sp. SS1 xylanase was found to be an endoxylanase (Fig. 3). The spots of standard xylose, standard xylan, and xylanase-treated xylan were applied on TLC plate. Xylan did not move much because of its high molecular weight, xylose being of the lowest molecular weight moved ahead among all, while xylanase-treated xylan showed movement which was in between the xylan and xylose. These results indicate that the xylan has been cleaved endolytically by xylanase and may have produced a mixture of xylose, xylobiose, xylotriose and xylooligomers. Similarly, Clostridium cellulovorans xylanase has

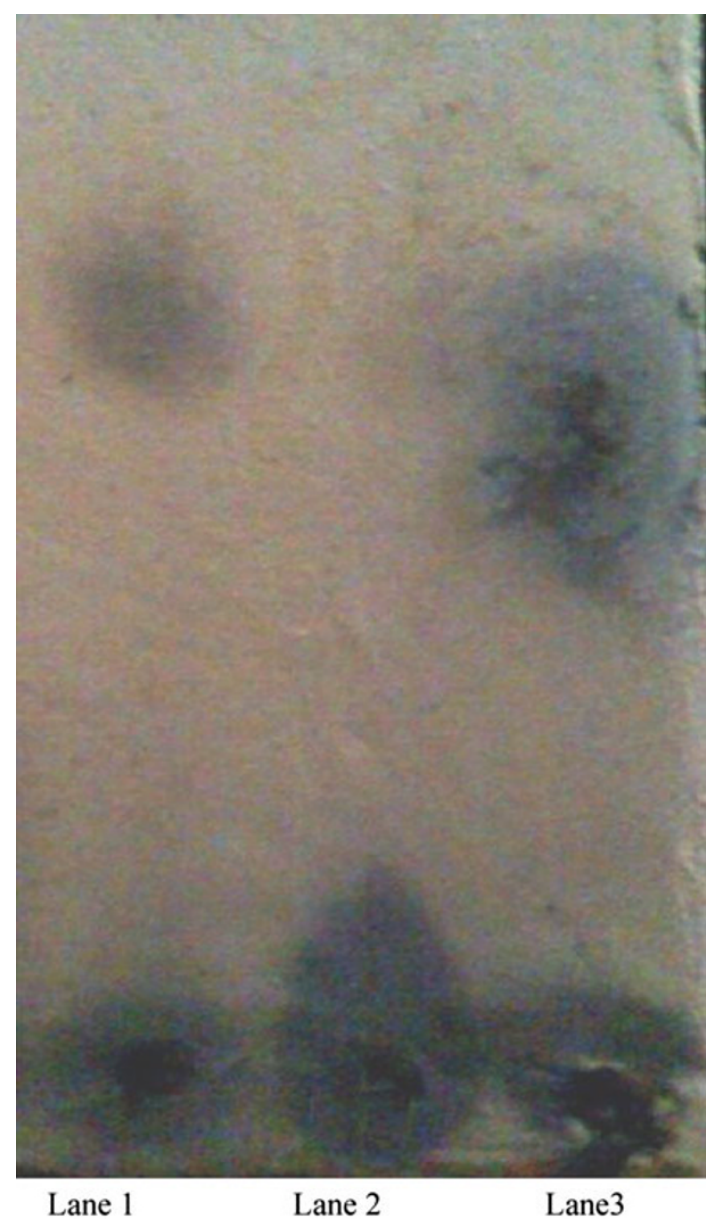

Fig. 3 Demonstration of endoxylanolytic nature of Penicillium sp. SS1 xylanase. Lane 1 and lane 2 indicate standard xylose control and standard xylan control, respectively, while the lane 3 represents xylanase-treated xylan, showing the presence of xylan degradation products (xylose, xylobiose, xylotriose and xylooligosaccharides) due to action of xylanase on xylan 
been reported to produce a mixture of xylose, xylobiose, xylotriose and xylooligomers from xylan (Kosugi et al. 2001).

Xylanase production using agriculture-based crude carbon sources

Since the cost of the substrate plays a crucial role in the economics of any industrial production process, therefore, low-value crude agriculture-based raw materials may be employed as cost-effective substrates for xylanase production. India being blessed with rich agricultural heritage there is no dearth of agricultural-based residues. Utilization of agricultural residues for enzyme production may serve dual purpose, on one side it provides a valuable product (enzyme) and on the other side also help solving environmental waste disposal problem. In the present study, various carbon sources viz. wheat bran, rice bran and sawdust were employed as substrates for xylanase production. Penicillium sp. SS1, although showed the maximum xylanase production on xylan $(40.1 \mathrm{IU} / \mathrm{ml})$, but substantial xylanase activity was observed on crude carbon sources like wheat bran $(21.8 \mathrm{IU} / \mathrm{ml})$, rice bran $(20.6 \mathrm{IU} / \mathrm{ml})$ and sawdust (10.7 IU/ml), as well (Fig. 4). Maximum xylanase production was reported on the fourth day of cultivation in all the cases.

When the xylanases are to be used for the pulp and paper industries then the enzyme preparations must be free of cellulases else the cellulose fibres may be damaged. In the present study, the enzyme preparation did not show FPase activity at all, however, displayed negligible carboxymethyl cellulase activity $(0.088 \mathrm{IU} / \mathrm{ml})$. Thus, such enzyme preparation may have potential to be used in pulp and paper industries. Many researchers have reported moderate or negligible or even a total absence of cellulase activity in xylanase preparation (Bakir et al. 2001). However, xylanases with cellulase activity can be successfully

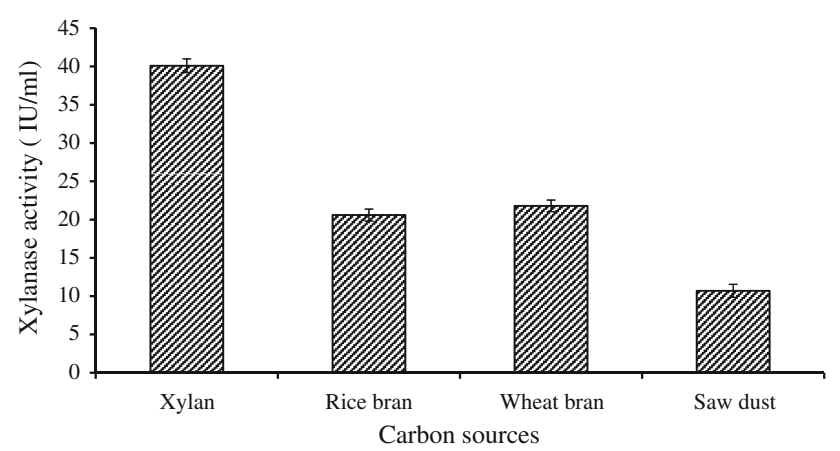

Fig. 4 Xylanase production by Penicillium sp. SS1 on agriculturebased carbon sources. Xylan of the production medium was replaced with either of the carbon source and fermentation was conducted $(180 \mathrm{rpm})$ at $30^{\circ} \mathrm{C}$. Error bars indicate standard deviations used for alternative applications, i.e. for the food and feed industry, lignocellulose biotransformation industries and in silage preparation (Sharma and Bajaj 2005). There are many reports on xylanase production using agricultural based crude carbon sources (Bakri et al. 2003; Min et al. 2007; Sudan and Bajaj 2007; Bajaj and Singh 2010; Singh et al. 2011). Rice husk and wheat bran were found to be good substrates for xylanase production by Aspergillus niveus RS2 (Sudan and Bajaj 2007). Rice straw and wheat bran in ratio of $3: 1$ proved to be the best substrate for maximum xylanase production from A. niger KK2 (Min et al. 2007). Streptomyces sp. $7 \mathrm{~b}$ showed maximum xylanase production on wheat bran (Bajaj and Singh 2010).

Effect of nitrogen sources on xylanase production

Formation of extracellular enzymes is influenced by the availability of nitrogen source as it is the ultimate precursor for protein synthesis. Furthermore, nitrogen source can significantly affect the $\mathrm{pH}$ of medium during the course of fermentation, and hence enzyme activity and stability may also get influenced. In the present study, the usual nitrogen source of the production medium was replaced with different alternative nitrogen sources viz. yeast extract, urea, soybean meal or peptone $(0.5 \%, \mathrm{w} / \mathrm{v})$. Among these, the yeast extract supported maximum enzyme production $(45.74 \mathrm{IU} / \mathrm{ml})$ on fourth day of fermentation. Soybean meal and ammonium sulphate also resulted in significantly high enzyme activity (22.2 and $20 \mathrm{IU} / \mathrm{ml}$, respectively), however, urea and peptone as nitrogen sources caused repression in xylanase synthesis (Fig. 5). Similar to above results, yeast extract has been reported as one of the best nitrogen source for xylanase production by different fungal species (Sudan and Bajaj 2007; Min et al. 2007). In contrast, Sharma and Bajaj (2005) reported that soybean meal is the best nitrogen source while yeast extract and gelatin are moderately good for xylanase production by Streptomyces sp. CD3. In another study, tryptone supported higher xylanase production as compared to yeast extract and soybean meal (Bajaj and Singh 2010). Combination of yeast extract and peptone were found to be the best for maximum xylanase production by Penicillium canescens 10-10c (Bakri et al. 2003). Urea has been reported as recalcitrant source of nitrogen for xylanase production as it leads to repression in xylanase biosynthesis while soy flour has been found to be the most conditioned nitrogen source (Bakri et al. 2003).

Effect of initial medium $\mathrm{pH}$ on xylanase production

For studying the effect of initial $\mathrm{pH}$ of medium on xylanase titre, production medium with $1 \%$ xylan and $0.5 \%$ yeast extract was used and adjusted at $\mathrm{pH} \mathrm{8,9}$ and 10. Maximum 


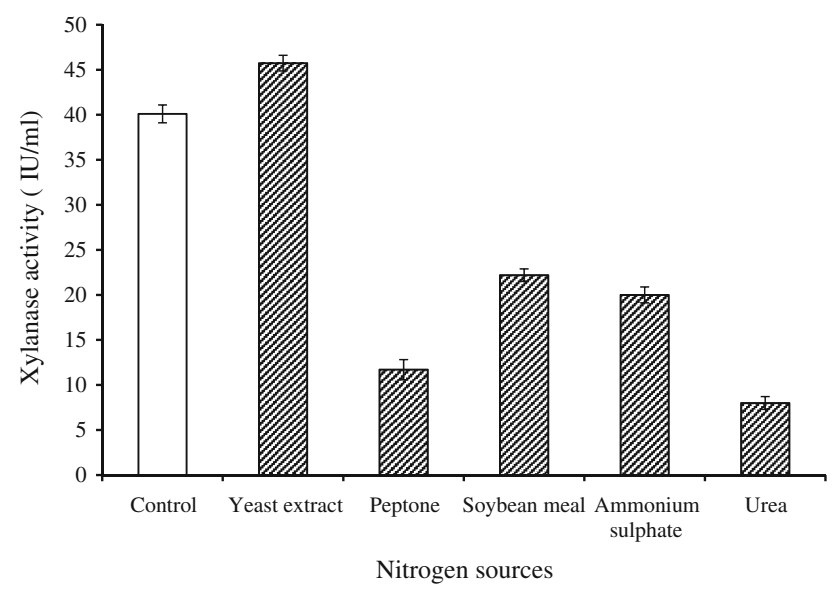

Fig. 5 Xylanase production by Penicillium sp. SS1 using different nitrogen sources. The usual nitrogen source of the production medium was replaced with either of the nitrogen source and fermentation was conducted. Error bars show standard deviations

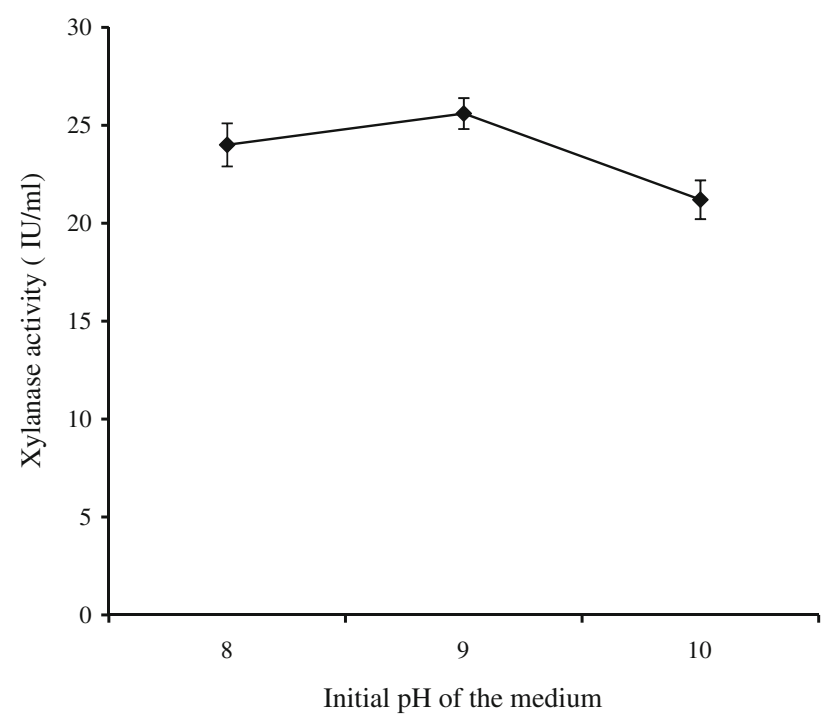

Fig. 6 Effect of initial medium $\mathrm{pH}$ on xylanase production by Penicillium sp. SS1. pH of the production medium was adjusted with sodium carbonate $(2 \%, \mathrm{w} / \mathrm{v})$ and fermentation was conducted at $30{ }^{\circ} \mathrm{C}$ on shaker (180 rpm). Error bars show standard deviations

xylanase activity was observed in medium at $\mathrm{pH} 8$ and 9 , i.e. 24 and $25.6 \mathrm{IU} / \mathrm{ml}$, respectively, while at $\mathrm{pH} 10$, xylanase activity was slightly decreased, i.e. $21.2 \mathrm{IU} / \mathrm{ml}$ (Fig. 6). The results indicate that the selected organism Penicillium sp. SS1 is quite alkalitolerant and is not only capable of growing well but also producing sufficiently high xylanase titre at high alkaline $\mathrm{pH}$. Majority of fungal species have been reported to produce maximum xylanase at acidic pH (Carmona et al. 1998; Subramanian and Prema 2000). There are reports of xylanase production at alkaline $\mathrm{pH}$ also. A. niveus $\mathrm{RS} 2$ showed a greater xylanase production at a neutral and slightly alkaline $\mathrm{pH}(\mathrm{pH} 8)$ than at an acidic and high alkaline pH (Sudan and Bajaj 2007). However, Ruckmanl and Rajendran (2001) reported maximum xylanase production from A. flavus at $\mathrm{pH} 9$.

Effect of $\mathrm{pH}$ on enzyme activity

The majority of xylanases reported to date are optimally active in the acidic, neutral or slight alkaline $\mathrm{pH}$ range (Subramanian and Prema 2000; Sudan and Bajaj 2007). From the application point of view, xylanases that are active and stable at alkaline $\mathrm{pH}$ range are important. Xylanase assay was conducted at different $\mathrm{pH}$ by employing appropriate buffers. Maximum xylanase activity was observed at pH $8(28.8 \mathrm{IU} / \mathrm{ml})$ and it decreased slightly at $\mathrm{pH} 7(23.8 \mathrm{IU} / \mathrm{ml})$, however, substantial amount of enzyme activity was retained under high alkalinity, i.e. 24 and $21.8 \mathrm{IU} / \mathrm{ml}$ at $\mathrm{pH} 9$ and $\mathrm{pH} 10$, respectively, as shown in Fig. 7. Results indicate that enzyme is highly alkalitolerant and may comply with the industrial processes (pulp and paper) which are carried out at higher $\mathrm{pH}$. Xylanase from $P$. citrinum showed $\mathrm{pH}$ optima of 8.5 (Dutta et al. 2007) while that from Talaromyces thermophilus was maximally active at $\mathrm{pH} 7-8$ (Maalej et al. 2009).

\section{Effect of temperature on enzyme activity}

For studying the effect of temperature on enzyme activity, the enzyme assay was carried out at different temperatures $\left(30-90{ }^{\circ} \mathrm{C}\right)$. Maximum xylanase activity was reported at $50{ }^{\circ} \mathrm{C}(32.4 \mathrm{IU} / \mathrm{ml})$, however, substantially high activity was observed at $60{ }^{\circ} \mathrm{C}(21 \mathrm{IU} / \mathrm{ml})$ as presented in Fig. 8 . But at still higher temperatures $\left(70-90{ }^{\circ} \mathrm{C}\right)$ activity decreased. As most of the industrial processes are accomplished at quite higher temperatures, therefore, it is highly desirable that the enzyme preparation intended to be used

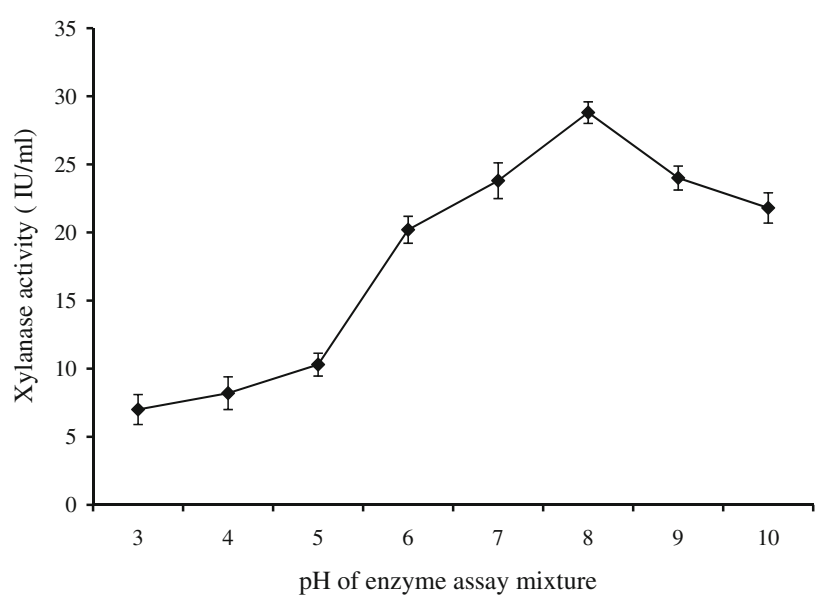

Fig. 7 Effect of $\mathrm{pH}$ on activity of Penicillium sp. SS1 xylanase. Xylanase assay was performed at different $\mathrm{pH}$ (3-10) using appropriate buffers. Error bars indicate standard deviations 


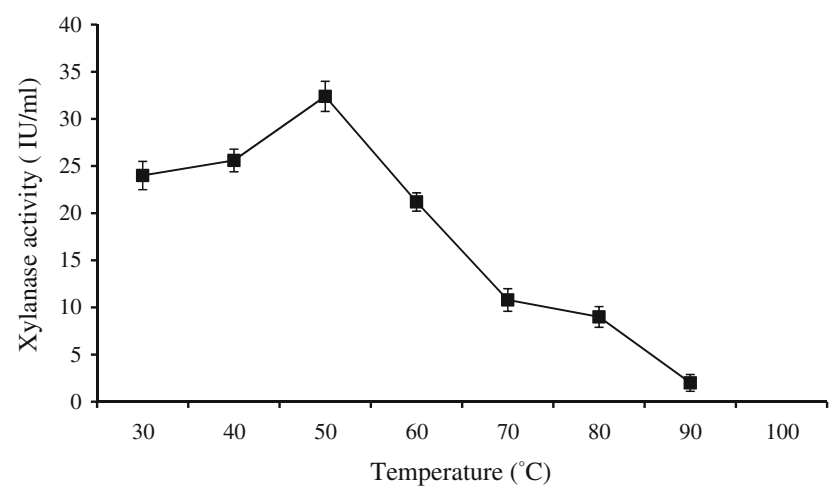

Fig. 8 Effect of temperature on activity of Penicillium sp. SS1 xylanase. Xylanase assay was conducted at different temperatures $\left(30-90{ }^{\circ} \mathrm{C}\right)$. Error bars show standard deviations

for such processes must be capable of withstanding high temperatures. Fungal xylanases typically have temperature optima of about $50{ }^{\circ} \mathrm{C}$ (Ruckmanl and Rajendran 2001; Shah and Madamwar 2005; Sudan and Bajaj 2007; Dutta et al. 2007; Murthy and Naidu 2010). However, the xylanases with higher temperature optima have also been reported which could have potential to be used in paper and pulp industry. T. thermophilus xylanase has been reported to have temperature optima of $75-80{ }^{\circ} \mathrm{C}$ (Maalej et al. 2009).

\section{Thermostability of xylanase}

The enzyme preparation was pre-incubated at temperatures ranging from 50 to $90{ }^{\circ} \mathrm{C}$ for different time periods (30-90 min) and residual activity was assayed. At $50-60{ }^{\circ} \mathrm{C}$ the enzyme retained very high activity up to $30-60 \mathrm{~min}$ (91-100\%), however, prolonged incubation (90 $\mathrm{min}$ ) caused considerable activity reduction (residual activity 63-68\%) as shown in Fig. 9. At $70{ }^{\circ} \mathrm{C}$ xylanase showed substantial activity (63-72\%) up to 30-60 min but considerable activity reduction occurred after $90 \mathrm{~min}$ (residual activity $45 \%$ ). Preincubation of enzyme at still higher temperature $\left(80^{\circ} \mathrm{C}\right)$ resulted in residual activity of $34-40 \%$ after $30-60 \mathrm{~min}$, while after $90 \mathrm{~min}$ residual activity was $23 \%$. At $90{ }^{\circ} \mathrm{C}$ almost complete inactivation of xylanase was observed (Fig. 9). Substantial stability of the xylanase at elevated temperature reflects that enzyme could have potential industrial significance particularly in processes which are accomplished at higher temperatures. A. foetidus xylanase retained residual activity of 71 and $20 \%$ after $30 \mathrm{~min}$ of exposure at 50 and $60{ }^{\circ} \mathrm{C}$, respectively, while at $70{ }^{\circ} \mathrm{C}$ the enzyme was completely inactivated within $30 \mathrm{~min}$ (Shah and Madamwar 2005). A. versicolor xylanase I and xylanase II showed half-lives of 17 and $1.7 \mathrm{~min}$, respectively, at $60{ }^{\circ} \mathrm{C}$ (Carmona et al. 1998). Similarly, Sudan and Bajaj (2007) reported that $A$. niveus $\mathrm{RS} 2$ xylanase retained $97,88.9$ and

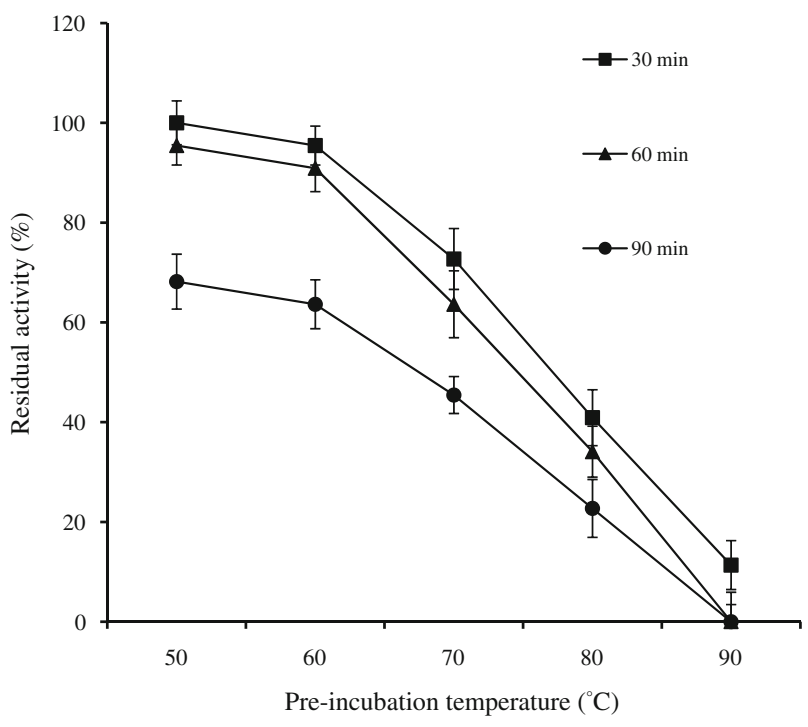

Fig. 9 Thermostability of xylanase from Penicillium sp. SS1. Enzyme was preincubated at different temperatures $\left(50-90^{\circ} \mathrm{C}\right)$ for varying time periods (30-90 $\mathrm{min}$ ) and then assayed for residual activity. Error bars show standard deviations

$70.9 \%$ of the initial activity after 20,30 and 40 min of incubation at $50{ }^{\circ} \mathrm{C}$, respectively, while at $60{ }^{\circ} \mathrm{C}$ the residual activity after $20 \mathrm{~min}$ was $52.9 \%$, and after $60 \mathrm{~min}$ a complete loss of activity was observed.

The results indicate that the selected organism Penicillium sp. SS1 is capable of growing under high alkaline conditions, and is able to use agriculture-based crude carbon and nitrogen sources for the production of xylanase. The xylanase so produced is highly alkalistable and thermostable. Considering vast biotechnological applications of alkalistable and thermostable xylanases, this xylanase may be of potential commercial significance. Further studies on the organism and its xylanase must be carried to better understand the organism and the enzyme.

Acknowledgments Dr. Bijender Kumar Bajaj thanks the Department of Science and Technology, Ministry of Science and Technology, Govt. of India, for financial support (Project Ref. SR/SO/BB-66/ 2007), and Director, School of Biotechnology, University of Jammu, Jammu, for kindly extending necessary laboratory facilities for concluding this work.

Open Access This article is distributed under the terms of the Creative Commons Attribution License which permits any use, distribution and reproduction in any medium, provided the original author(s) and source are credited.

\section{References}

Bajaj BK, Singh NP (2010) Production of xylanase from an alkalitolerant Streptomyces sp. 7b under solid-state fermentation, its purification, and characterization. Appl Biochem Biotechnol 162:1804-1818 
Bakir U, Yavascoglu S, Guvence F, Erroyin A (2001) An endo- $\beta-1$, 4-xylanase from Rhizopus oryzae: production, partial purification and biochemical characterization. Enzym Microb Technol 29:328-334

Bakri Y, Jacques P, Thonart P (2003) Xylanase production by Penicillium canescens $10-10 \mathrm{c}$ in solid state fermentation. Appl Biochem Biotechnol 108:737-748

Beg QA, Kapoor M, Mahajan G, Hoondal S (2001) Microbial xylanases and their industrial applications: a review. Appl Microbiol Biotechnol 56:326-338

Bocchini DA, Gomes E, Da Silva R (2008) Xylanase production by Bacillus circulans D1 using maltose as carbon source. Appl Biochem Biotechnol 146:29-37

Carmona EC, Brochetto-braga MR, Pizzirani-kleiner AA, Jorge JA (1998) Purification and biochemical characterization of an endoxylanase from Aspergillus versicolor. FEMS Microbiol Lett 166:311-315

Dutta T, Sengupta R, Sahoo R, Ghosh S (2007) A novel cellulase-free alkaliphilic xylanase from alkalitolerant Penicillium citrinum: production, purification and characterization. Lett Appl Microbiol 44:206-211

Kosugi A, Murashima K, Doi RH (2001) Characterization of xylanolytic enzymes in Clostridium cellulovorans: expression of xylanase activity dependent on growth substrates. J Bacteriol 24:7037-7043

Kuhad RC, Singh A (1993) Lignocellulosic biotechnology: current and future prospects. Crit Rev Biotechnol 13:151-172

Li Y, Liu Z, Zhao H (2007) Production of xylanase from a newly isolated Penicillium sp. ZH-30. World J Microbiol Biotechnol 23:837-843

Liu C, Sun ZT, Du JH, Wang J (2008) Response surface optimization of fermentation conditions for producing xylanase by Aspergillus niger SL-05. J Ind Microbiol Biotechnol 35:703-711

Maalej I, Belhaj I, Belghith H (2009) Highly thermostable xylanase of the thermophilic fungus Talaromyces thermophilus: purification and characterization. Appl Biochem Biotechnol 158:200-212
Miller GL (1959) Use of dinitrosalicylic acid for the determination of reducing sugar. Anal Chem 31:426-428

Min BJ, Park YS, Kang SW, Song YS, Lee JH, Park C, Kim CW, Kim SW (2007) Statistical optimization of medium components for the production of xylanase by Aspergillus niger KK2 in submerged cultivation. Biotechnol Bioprocess Eng 12:302-307

Murthy PS, Naidu MM (2010) Production and application of xylanase from Penicillium sp. utilizing coffee by-products. Food Bioprocess Technol. doi:10.1007/s11947-010-0331-7

Nagar S, Mittal A, Kumar D, Kumar L, Kuhad RC, Gupta VK (2011) Hyper production of alkali stable xylanase in lesser duration by Bacillus pumilus SV-85S using wheat bran under solid state fermentation. New Biotechnol. doi:10.1016/j.nbt.2010.12.004

Ruckmanl A, Rajendran A (2001) Production of cellulase-poor xylanase by an alkalitolerant strain of Aspergillus flavus. Indian J Microbiol 41:115-118

Shah AR, Madamwar D (2005) Xylanase production by a newly isolated A. foetidus strain and its characterization. Process Biochem 40:763-777

Sharma P, Bajaj BK (2005) Production and partial characterization of alkali-tolerant xylanase from an alkaliphilic Streptomyces $s p$. CD3. J Sci Ind Res 64:688-698

Singh S, Dutt D, Tyagi CH, Upadhyaya JS (2011) Bio-conventional bleaching of wheat straw soda-AQ pulp with crude xylanases from SH-1 NTCC-1163 and SH-2 NTCC-1164 strains of Coprinellus disseminatus to mitigate AOX generation. New Biotechnol 28:47-57

Subramanian S, Prema P (2000) Cellulase-free xylanases from Bacillus and other microorganisms. FEMS Microbiol Lett 183:1-7

Sudan R, Bajaj BK (2007) Production and biochemical characterization of xylanase from an alkalitolerant novel species Aspergillus niveus RS2. World J Microbiol Biotechnol 23:491-500 